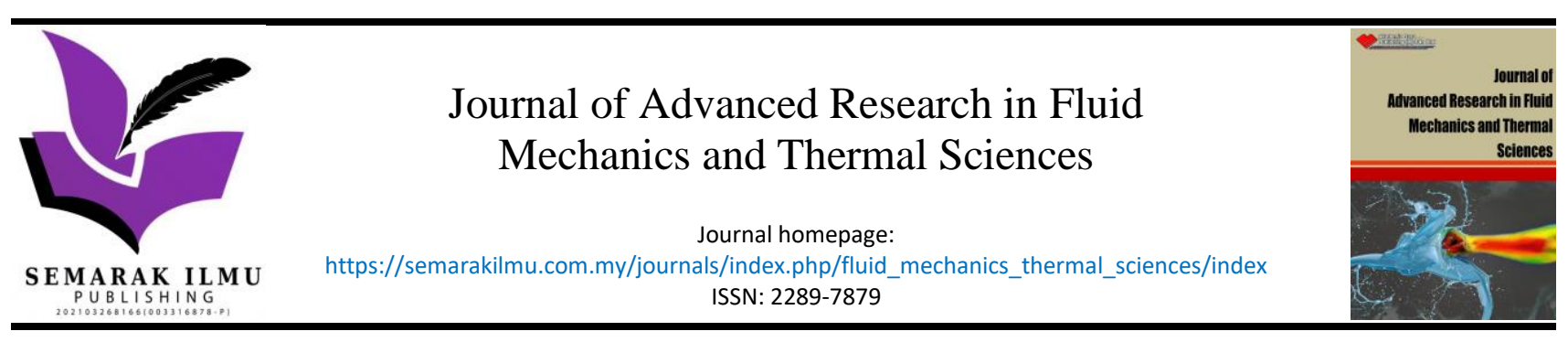

\title{
Mathematical Model Represents the Effect of Flexible Endoscopy on Suspension Fluid Flow
}

\author{
Amal Bahnasy ${ }^{1, *}$, A. M. Abdel-Wahab ${ }^{1, *}$ \\ 1 Department of Mathematics, Faculty of Science, Al-Azhar University (Girls), Nasr City, Egypt
}

\section{ARTICLE INFO ABSTRACT}

\section{Article history:}

Received 27 April 2021

Received in revised form 13 October 2021

Accepted 27 October 2021

Available online 19 November 2021

\section{Keywords:}

Peristaltic; suspension; annular tube; flexible endoscopy; pressure drop; frictional force

\begin{abstract}
In this manuscript, peristaltic transport induced by a sinusoidal traveling wave in the case for a viscous incompressible Newtonian fluid mixed with rigid spherical particles in the presence of a flexible inner tube, where the inner tube is also moving with a sinusoidal traveling wave of moderate amplitude is studied. The governing equations of the mixture (fluid-particle suspension) are written in two-dimensional cylindrical coordinates. The long-wavelength approximation is used to simplify the system of equations ( $\delta<<1)$. The velocities distribution for both fluid and particles are obtained and evaluated numerically with discussion for special cases. The flow rate, pressure drop, friction forces and shear stress at the outer and inner walls of tubes are derived and represented graphically. In the urinary system, peristalsis is due to involuntary muscular contractions of the ureter wall which drives urine from the kidneys to the bladder through the ureters. A mathematical analysis of peristaltic flow with application to the ureter in presence of flexible endoscopy (Peristaltic Endoscope) is taken as a real application in this study. Finally, conclusions of the research and recommendations for future work are discussed. The results obtained may be relevant to the transport of other physiological fluids and industrial applications in which peristaltic pumping is used.
\end{abstract}

\section{Introduction}

The modeling of two-phase flows has a tremendous variety of engineering and scientific applications, e.g., pollution dispersion in the atmosphere, fluidization processes and aerosol deposition in spray medication. The sedimentation of particles in a liquid is of interest in many chemical engineering processes, where erythrocyte sedimentation has become a standard clinical test such as kidney stones in the ureter Jimenez-Lozano et al., [14], embryo implantation in the ureter and blood flows capillaries Srivastava and Srivastava [34]. The studies which related to the dusty gases were concerned by Saffman who carried out pioneering work on the stability of a laminar flow of a dusty gas by introducing relaxation parameter. By describing the motion of a gas carrying small dust

\footnotetext{
* Corresponding author.

E-mail address: amlbahnasi@azhar.edu.eg

* Corresponding author.

E-mail address: am_abdelwahab@yahoo.com;am_abdelwahab@azhar.edu.eg
}

https://doi.org/10.37934/arfmts.89.1.4261 
particles. The equations are derived to satisfy small disturbances of a steady laminar flow. The effect of the dust is described by two parameters; the concentration of dust and a relaxation time Saffman [29]. The problem of the flow of a conducting dusty gas occupying a semi infinite space in the presence of a transverse magnetic field was studied by Baral [5] while Rao [26] studied the unsteady flow of a dusty viscous liquid in a channel and a pipe. Also discussed the unsteady flow of a dusty viscous liquid through a circular cylinder under the influence of a pressure gradient varying in magnitude but not in direction.

In Biological system of hydrodynamics, the continuum theory of mixtures is very helpful because it provides useful information about various diverse subjects like movement of microorganisms, deposition of different particle in the respiratory tract, rheology of blood and diffusion of proteins. About this topic there are a lot of studies which take the peristaltic transport on the walls Aarts and Ooms [1], Antanovskii and Ramkissoon [2], El-Misery et al., [8], Hung and Brown [12], Mekheimer et al., [21], Srivastava and Saxena [34], Srivastava and Srivastava [36] and Srivastava and Srivastava [37].

Also, this transport has great importance in a wide range of areas like fluidization, flow in rocket tubes, combustion, paint spraying, petroleum industry and in the purification of crude oil. The basic principles of peristaltic explained by Fung and Yih [9], Hung and Brown [12], Jaffrin and Shapiro [13], Medhavi and Singh [18], Medhavi and Singh [19], Muthuraj et al., [23], Shapiro et al., [33], Srivastava and Srivastava [36], Srivastava and Srivastva [38] and Takabatake and Ayakawa [41].

Mekheimer et al., [20] discuss the peristaltic transport of a particle-fluid mixture through the gap between eccentric cylinders take the outer flexible cylinder with a peristaltic wave on its wall and the inner one is rigid uniform tube moving with constant velocity.

The flow between coaxial tubes where outer tube (uniform or nonuniform) are found in many applications such as the endoscopy problem, catheterized artery and exerted natural gases Srivastava and Srivastava [40] and Nagarani et al., [24].

In modern medicine endoscopy and catheters have many uses which enable the physician to look inside closed tubes (gastrointestinal tract, respiratory tract, the urinary tract). There are many topics about the use and effects of catheters on flows such as Back [3], Back et al., [4], MacDonald [15], Medhavi [17], Roos and Lykoudis [28], Sankar and Hemlatha [30] and Sarkar and Jayaraman [31]. All of these topics, the catheter or the inner tube was supposed to be rigid. Currently, endoscopes are either semi-rigid or completely rigid tubes that can only be inserted with the exertion of considerable force by a physician. As a consequence, they are liable to damage the internal vessels of the body, and may also induce patient discomfort during insertion. Even catheters, which are more flexible, can do damage when pushed into the different vessels of the body Grove and Pevec [10] and Wu et al., [44]. Mangan et al., [16] have successfully demonstrated a prototype of flexibly endoscope that could move through tubes and around curves using peristaltic locomotion. A device that could move through curving and tortuous spaces would find many applications in medicine and in industry. It is also possible to use the device as a catheter for infusion or withdrawal of fluids.

Rachid et al., [25], Rachid and Ouazzani [26], treated with this problem under the consideration of flexible inner tube. Recently, there are explanation to peristaltic induced flow of blood through narrow catheterized arteries as a view of the observations of Srivastava [39]. Mekheimer and Ramadan [22] studied the peristaltic flow of Jeffrey nanofluid containing motile gyrotactic microorganisms through an endoscope with non-linear thermal radiation, magnetic field, and viscous dissipation.

With the above presentation in mind, the researchers try to introduce new case of annular flexible tubes the goal of this investigation to study the effect of inner flexible tube on the axial velocities, pressure drop and frictional force of particle-fluid suspension in a circular tube moving by peristaltic transport in the presence of inner tube where inner wall is flexible moving with a sinusoidal wave. In 
this paper the results will be represent graphically and numerically taken experimental data into account and discuss this results.

Medhavi [17], Saxena and Srivastava [32] and Shapiro et al., [33] are special cases of this problem. The researcher suggested here this formulation may be applied to explain the inserted flexible endoscopy into gastrointestinal, respiratory or the urinary tract.

\section{Formulation of the Problem}

Consider the flow of a particle-fluid suspension through the gap between two coaxial peristaltic tubes where the sinusoidal waves travelling down their walls, (see Figure 1) [45].

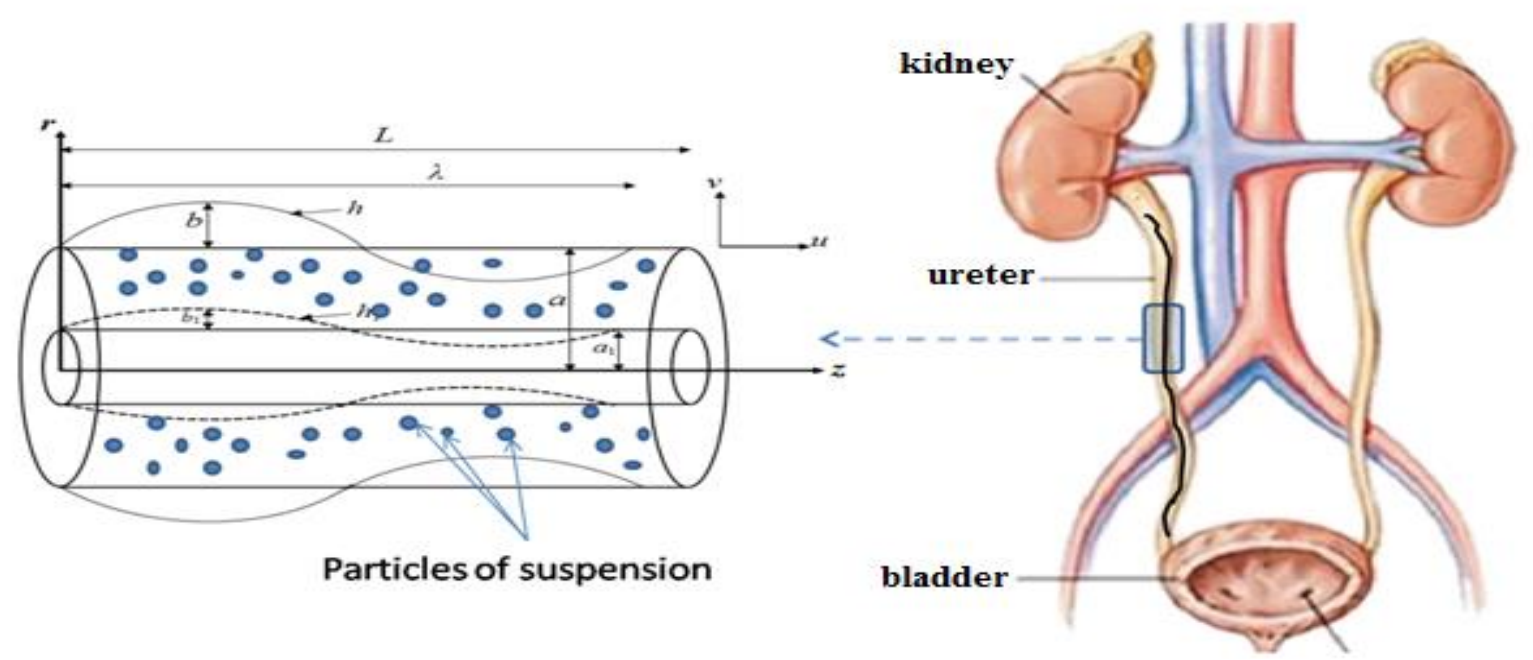

Fig. 1. Geometry of the problem

Consider the flow of a particle-fluid mixture in a circular cylindrical tube of radius $(a)$ with an inserted tube of radius $\left(a_{1}\right)$. The outer tube is flexible (sinusoidal peristaltic waves) takes the form

$H(z, t)=a+b \sin \frac{2 \pi}{\lambda}(z-c t)$

where $b$ is amplitude of the wave on outer tube, $\lambda$ is wavelength, $c$ is speed of the wave propagation, $t$ is time and $(r, z)$ are (radial coordinate, axial coordinate). Also, the inner tube wall is flexible (sinusoidal peristaltic waves) takes the form

$H_{1}(z, t)=a_{1}+b_{1} \sin \frac{2 \pi}{\lambda}(z-c t)$.

where $b_{1}$ is amplitude of the wave on the inner tube; $0 \leq b \leq a-a_{1}$ and $b_{1}<b$. The gap between two coaxial tubes fill with particle-fluid suspension which governing by the following system of equations Srivastava and Srivastva [38] 


\section{Fluid phase:}

$$
\begin{aligned}
& (1-C) \rho_{f}\left[\frac{\partial u_{f}}{\partial t}+u_{f} \frac{\partial u_{f}}{\partial z}+v_{f} \frac{\partial u_{f}}{\partial r}\right]= \\
& -(1-C) \frac{\partial P}{\partial z}+(1-C) \mu_{s}(C)\left[\frac{1}{r} \frac{\partial}{\partial r}\left(r \frac{\partial u_{f}}{\partial r}\right)+\frac{\partial^{2} u_{f}}{\partial z^{2}}\right]+C S\left(u_{p}-u_{f}\right) \\
& (1-C) \rho_{f}\left[\frac{\partial v_{f}}{\partial t}+u_{f} \frac{\partial v_{f}}{\partial z}+v_{f} \frac{\partial v_{f}}{\partial r}\right]= \\
& -(1-C) \frac{\partial P}{\partial r}+(1-C) \mu_{s}(C)\left[\frac{1}{r} \frac{\partial}{\partial r}\left(r \frac{\partial v_{f}}{\partial r}\right)-\frac{v_{f}}{r^{2}}+\frac{\partial^{2} v_{f}}{\partial z^{2}}\right]+C S\left(v_{p}-v_{f}\right) \\
& \frac{1}{r} \frac{\partial}{\partial r}\left[r(1-C) v_{f}\right]+\frac{\partial}{\partial z}\left[(1-C) u_{f}\right]=0
\end{aligned}
$$

\section{Particle phase:}

$$
\begin{aligned}
& C \rho_{p}\left[\frac{\partial u_{p}}{\partial t}+u_{p} \frac{\partial u_{p}}{\partial z}+v_{p} \frac{\partial u_{p}}{\partial r}\right]=-C \frac{\partial P}{\partial z}+C S\left(u_{f}-u_{p}\right), \\
& C \rho_{p}\left[\frac{\partial v_{p}}{\partial t}+u_{p} \frac{\partial v_{p}}{\partial z}+v_{p} \frac{\partial v_{p}}{\partial r}\right]=-C \frac{\partial P}{\partial r}+C S\left(v_{f}-v_{p}\right), \\
& \frac{1}{r} \frac{\partial}{\partial r}\left(r C v_{p}\right)+\frac{\partial}{\partial z}\left(C u_{p}\right)=0 .
\end{aligned}
$$

where

$C$ is volume fraction of the particulate phase (concentration), $\left(\rho_{f}, \rho_{p}\right)$ actual density of the fluid and particles respectively,

$\left((1-C) \rho_{f},(C) \rho_{p}\right)$ is fluid phase and particulate phase densities, respectively,

$P$ is pressure,

$\mu_{s}(C) \equiv \mu_{s}$ is mixture viscosity and

$S$ is drag coefficient of interaction for the force exerted by one phase on the other. Concentration of particles is small enough to neglect the interaction between them. The volume fraction density $C$ of the particles is constant Srivastava and Srivastava [35].

$$
\mu_{s}(C)=\frac{\mu_{0}}{1-m C}
$$


where $m=0.07 \exp \left[2.49 C+\frac{1107}{T} e^{-1.69 C}\right]$ with $\mu_{0}$ is fluid viscosity (suspending medium), $T$ temperature of the mixture measured in absolute scale $(k)$ and $\mu_{s}$ is reasonably accurate up to $C=0.6$ Charm and Kurland [7], Srivastava and Srivastava [36]. The drag coefficient of interaction is given by as Tam [42]

$S=\frac{9}{2} \frac{\mu_{0}}{a_{0}^{2}}\left[\frac{4+3\left[8 C-3 C^{2}\right]^{\frac{1}{2}}+3 C}{(2-3 C)^{2}}\right]$

where $a_{0}$ radius of a particle. The boundary conditions of motion are given by

$$
\left.\begin{array}{llll}
u_{f}=0 \quad, & v_{f}=\frac{\partial H(z, t)}{\partial t} & \text { at : } & r=H(z, t), \\
u_{f}=0 \quad, & v_{f}=\frac{\partial h_{1}(z, t)}{\partial t} & \text { at : } & r=H_{1}(z, t) .
\end{array}\right\}
$$

introducing the following dimensionless variables

$$
\left.\begin{array}{ll}
r^{\prime}=\frac{r}{a}, \quad z^{\prime}=\frac{z}{\lambda}, \quad u_{f}^{\prime}=\frac{u_{f}}{c}, \quad u_{p}^{\prime}=\frac{u_{p}}{c}, \quad v_{p}^{\prime}=\frac{\lambda v_{p}}{a c}, \quad v_{f}^{\prime}=\frac{\lambda v_{f}}{a c}, \\
t^{\prime}=\frac{c t}{\lambda}, \quad P^{\prime}=\frac{a^{2} P}{\lambda c \mu_{0}}, \quad S^{\prime}=\frac{S a^{2}}{\mu_{0}}, \quad \mu=\frac{\mu_{s}}{\mu_{0}}, \quad H^{\prime}=\frac{H}{a}, \quad H_{1}^{\prime}=\frac{H_{1}}{a} .
\end{array}\right\}
$$

Using (12) in (3-8) and (11) then dropping (') the system of motion become, for fluid phase

$$
\begin{aligned}
& (1-C) \delta \operatorname{Re}\left[\frac{\partial u_{f}}{\partial t}+u_{f} \frac{\partial u_{f}}{\partial z}+v_{f} \frac{\partial u_{f}}{\partial r}\right]= \\
& -(1-C) \frac{\partial P}{\partial z}+(1-C) \mu\left[\frac{1}{r} \frac{\partial}{\partial r}\left(r \frac{\partial u_{f}}{\partial r}\right)+\delta^{2} \frac{\partial^{2} u_{f}}{\partial z^{2}}\right]+C S\left(u_{p}-u_{f}\right) \\
& (1-C) \delta^{3} \operatorname{Re}\left[\frac{\partial v_{f}}{\partial t}+u_{f} \frac{\partial v_{f}}{\partial z}+v_{f} \frac{\partial v_{f}}{\partial r}\right]= \\
& -(1-C) \frac{\partial P}{\partial r}+(1-C) \mu \delta^{2}\left[\frac{\partial}{\partial r}\left(\frac{1}{r} \frac{\partial\left(r v_{f}\right)}{\partial r}\right)+\delta^{2} \frac{\partial^{2} v_{f}}{\partial z^{2}}\right]+C S \delta^{2}\left(v_{p}-v_{f}\right) \\
& \frac{1}{r} \frac{\partial}{\partial r}\left[r(1-C) v_{f}\right]+\frac{\partial}{\partial z}\left[(1-C) u_{f}\right]=0
\end{aligned}
$$

and for particular phase 


$$
\begin{aligned}
& C\left(\frac{\rho_{p}}{\rho_{f}}\right) \delta \operatorname{Re}\left[\frac{\partial u_{p}}{\partial t}+u_{p} \frac{\partial u_{p}}{\partial z}+v_{p} \frac{\partial u_{p}}{\partial r}\right]=-C \frac{\partial P}{\partial z}+C S\left(u_{f}-u_{p}\right), \\
& C\left(\frac{\rho_{p}}{\rho_{f}}\right) \operatorname{Re} \delta^{3}\left[\frac{\partial v_{p}}{\partial t}+u_{p} \frac{\partial v_{p}}{\partial z}+v_{p} \frac{\partial v_{p}}{\partial r}\right]=-C \frac{\partial P}{\partial r}+C S \delta^{2}\left(v_{f}-v_{p}\right), \\
& \frac{1}{r} \frac{\partial}{\partial r}\left(r C v_{p}\right)+\frac{\partial}{\partial z}\left(C u_{p}\right)=0 .
\end{aligned}
$$

where $R e=\frac{\rho_{f} c a}{\mu_{0}}$ is Reynolds number, $\delta=\frac{a}{\lambda}$ is wave number.

Using the wave frame (moving with the speed $c$ ):

$$
\begin{array}{lll}
z^{\prime}=z-c t & , & r^{\prime}=r, \\
u^{\prime}=u-c & , & v^{\prime}=v .
\end{array}
$$

Substitution this frame in $(1,2)$ and dropping (')

$h(z)=a+b \sin \frac{2 \pi}{\lambda} z$

$h_{1}(z)=a_{1}+b_{1} \sin \frac{2 \pi}{\lambda} z$

with the boundary conditions:

$$
\begin{array}{llll}
u_{f}=-1, & v_{f}=-\frac{d h(z)}{d z} \quad \text { at }: & r=h(z)=1+\phi \sin 2 \pi z, \\
u_{f}=-1, & v_{f}=-\frac{d h_{1}(z)}{d z} \quad \text { at }: & r=h_{1}(z)=\varepsilon+\phi_{1} \sin 2 \pi z .
\end{array}
$$

where $\phi=b / a, \phi_{1}=b_{1} / a$ are the amplitude ratio for the outer and inner tubes respectively and $\varepsilon=a_{1} / a$ is eccentricity parameter.

\section{Method of Solution}

Using the long wavelength approximation $\delta \ll<1$ Shapiro et al., [33]. From (14) $\frac{\partial P}{\partial r}=0$ the pressure is not a function of $r$ then $\frac{\partial P}{\partial z} \equiv \frac{d P}{d z}$, as consequence (13) and (16) can be written as:

$(1-C) \frac{d P}{d z}=(1-C) \mu\left[\frac{1}{r} \frac{\partial}{\partial r}\left(r \frac{\partial u_{f}}{\partial r}\right)\right]+C S\left(u_{p}-u_{f}\right)$, 


$$
C \frac{d P}{d z}=C S\left(u_{f}-u_{p}\right)
$$

Using of Eq. (20) and Eq. (21) with boundary conditions Eq. (19) the expressions of the velocity profiles $u_{f}$ and ${ }^{u}$ given as:

$$
u_{f}=-1-\frac{(d P / d z)}{4 \mu(1-C)}\left\{h^{2}-r^{2}+\left(h^{2}-h_{1}^{2}\right) \frac{\ln \left(\frac{r}{h}\right)}{\ln \left(\frac{h}{h_{1}}\right)}\right\} \text {, }
$$

and

$$
u_{p}=-1-\frac{(d P / d z)}{4 \mu(1-C)}\left\{h^{2}-r^{2}+\left(h^{2}-h_{1}^{2}\right) \frac{\ln \left(\frac{r}{h}\right)}{\ln \left(\frac{h}{h_{1}}\right)}+\frac{4 \mu(1-C)}{S}\right\} \text {. }
$$

The instantaneous non-dimensional volumetric flow rate: $\left(q=\frac{q^{\prime}}{\pi a^{2} c} ; q^{\prime}\right.$ being the flow rate in wave frame of reference which is the same as laboratory frame of reference) which calculated in fluidparticle suspension as:

$q=2(1-C) \int_{h_{1}}^{h} r u_{f} d r+2 C \int_{h_{1}}^{h} r u_{p} d r$

Substitution from Eq. (22) and Eq.(23) in Eq.(24) the total flow rate $q$ take the form

$$
q=-\left(h^{2}-h_{1}^{2}\right)-\frac{\left(h^{2}-h_{1}^{2}\right)}{8 \mu(1-C)} \frac{d P}{d z}[\chi(z)]
$$

where

$$
\chi(z)=h^{2}+h_{1}^{2}+\beta-\frac{\left(h^{2}-h_{1}^{2}\right)}{\ln \left(\frac{h}{h_{1}}\right)} \text { is non-dimensional suspension parameter }
$$

with $\beta=\frac{8 \mu C(1-C)}{S}$.

Eq. (25) can be written as: 
$-\frac{d P}{d z}=\frac{8 \mu(1-C)\left(q+h^{2}-h_{1}^{2}\right)}{\left(h^{2}-h_{1}^{2}\right) \chi(z)}$.

To find the non-dimensional mean volumetric flow rate $(Q)$ over one period of the wave as in Shapiro et al., [33].

$$
Q=q+1+\frac{1}{2}\left(\phi^{2}-\phi_{1}^{2}\right)-\varepsilon^{2}
$$

Using Eq. (27) in Eq. (26) yields the mathematical relation for non-dimensional pressure drop $\Delta P$ across on wavelength, (which is the same in wave or laboratory frame of reference) and then it take the form:

$\Delta P=\int_{0}^{1}\left(-\frac{d P}{d z}\right) d z=2 \mu(1-C)\left\{\left(Q-1-\frac{1}{2}\left(\phi^{2}-\phi_{1}^{2}\right)+\varepsilon^{2}\right) I_{1}+I_{2}\right\}$.

with: $I_{1}=4 \int_{0}^{1} \frac{d z}{\left(h^{2}-h_{1}^{2}\right) \chi(z)}, \quad I_{2}=4 \int_{0}^{1} \frac{d z}{\chi(z)}$.

The friction force (at the wall) of the outer and inner tubes $F_{o}=F_{o}^{\prime} / \pi \lambda c \mu_{0}, F_{i}=F_{i}^{\prime} / \pi \lambda c \mu_{0}$ in (nondimensional forms) obtained as:

$$
\begin{aligned}
F_{0}= & \int_{0}^{1} h^{2}\left(-\frac{d P}{d z}\right) d z \\
& =2 \mu(1-C)\left\{\left(Q-1-\frac{1}{2}\left(\phi^{2}-\phi_{1}^{2}\right)+\varepsilon^{2}\right) I_{3}+I_{4}\right\}, \\
F_{i}= & \int_{0}^{1} h_{1}^{2}\left(-\frac{d P}{d z}\right) d z \\
& =2 \mu(1-C)\left\{\left(Q-1-\frac{1}{2}\left(\phi^{2}-\phi_{1}^{2}\right)+\varepsilon^{2}\right) I_{5}+I_{6}\right\} .
\end{aligned}
$$

with: $I_{3}=4 \int_{0}^{1} \frac{d z}{\left(1-\frac{h_{1}^{2}}{h^{2}}\right) \chi(z)}, \quad I_{4}=4 \int_{0}^{1} \frac{h^{2} d z}{\chi(z)}$

$$
I_{5}=4 \int_{0}^{1} \frac{d z}{\left(\frac{h^{2}}{h_{1}^{2}}-1\right) \chi(z)}, \quad I_{6}=4 \int_{0}^{1} \frac{h_{1}^{2} d z}{\chi(z)}
$$

By substitution Eq. (28) in Eq. (29) and Eq. (30) the pressure-flow rate and the friction forces-flow rate relationships are thus given in the following forms: 


$$
\begin{aligned}
& Q=1+\frac{1}{2}\left(\phi^{2}-\phi_{1}^{2}\right)-\varepsilon^{2}-\frac{I_{2}}{I_{1}}+\frac{\Delta P}{2 \mu(1-C) I_{1}}, \\
& F_{o}=2 \mu(1-C)\left\{I_{4}-\frac{I_{2} I_{3}}{I_{1}}+\frac{\Delta P I_{3}}{2 \mu(1-C) I_{1}}\right\}, \\
& F_{i}=2 \mu(1-C)\left\{I_{6}-\frac{I_{2} I_{5}}{I_{1}}+\frac{\Delta P I_{5}}{2 \mu(1-C) I_{1}}\right\} .
\end{aligned}
$$

The pressure rise $(-\Delta P)$ for zero time mean flow is obtained from Eq. (28):

$$
(-\Delta P)_{Q=0}=2 \mu(1-C)\left\{\left(1+\frac{1}{2}\left(\phi^{2}-\phi_{1}^{2}\right)-\varepsilon^{2}\right) I_{1}-I_{2}\right\} .
$$

The time-mean flow for zero pressure drop $\Delta P=0$ is given by applied on Eq. (31):

$$
Q=1+\frac{1}{2}\left(\phi^{2}-\phi_{1}^{2}\right)-\varepsilon^{2}-\frac{I_{2}}{I_{1}}
$$

The shear stress at walls of the outer and inner tubes given by (respectively):

$$
\begin{aligned}
& T_{1}=-\left.\mu \frac{\partial u_{f}}{\partial r}\right|_{r=h}, \\
& T_{2}=-\left.\mu \frac{\partial u_{f}}{\partial r}\right|_{r=h_{1}} .
\end{aligned}
$$

Using Eq. (22) in Eq. (36), Eq. (37) to get the following mathematical formula for $T_{1}$ and $T_{2}$ respectively:

$$
\begin{aligned}
& T_{1}=\frac{(d P / d z)}{4(1-C)}\left\{-2 h+\frac{\left(h^{2}-h_{1}^{2}\right)}{h \ln \left(\frac{h}{h_{1}}\right)}\right\}, \\
& T_{2}=\frac{(d P / d z)}{4(1-C)}\left\{-2 h_{1}+\frac{\left(h^{2}-h_{1}^{2}\right)}{h_{1} \ln \left(\frac{h}{h_{1}}\right)}\right\} .
\end{aligned}
$$


In the absence of peristaltic on the inner tube expressions for $\Delta P, F_{o}$, and $F_{i}$ in Eq. (28), Eq. (29) and Eq. (30) can be written as:

$$
\begin{aligned}
& \Delta P=2 \mu(1-C)\left\{\left(Q-1-\frac{1}{2} \phi^{2}\right) l_{1}+l_{2}\right\}, \\
& F_{o}=2 \mu(1-C)\left\{\left(Q-1-\frac{1}{2} \phi^{2}\right) l_{2}+l_{3}\right\}, \\
& F_{i}=2 \mu(1-C)\left\{\left(Q-1-\frac{1}{2} \phi^{2}\right) l_{4}+l_{5}\right\} .
\end{aligned}
$$

with: $l_{1}=4 \int_{0}^{1} \frac{d z}{\left(h^{2}-\varepsilon^{2}\right) \chi(z)}, \quad l_{2}=4 \int_{0}^{1} \frac{d z}{\left(1-\frac{\varepsilon^{2}}{h^{2}}\right) \chi(z)}, \quad l_{3}=4 \int_{0}^{1} \frac{h^{2} d z}{\left(1-\frac{\varepsilon^{2}}{h^{2}}\right) \chi(z)}$,

$$
l_{4}=4 \int_{0}^{1} \frac{d z}{\left(\frac{h^{2}}{\varepsilon^{2}}-1\right) \chi(z)}, \quad l_{5}=4 \int_{0}^{1} \frac{\varepsilon^{2} d z}{\left(1-\frac{\varepsilon^{2}}{h^{2}}\right) \chi(z)} .
$$

These results are the same as Medhavi [17].

Also, in the absence of inner tube (i.e $\varepsilon, \phi_{1} \rightarrow 0$ ) the formulas of $\Delta P$ and $F_{o}$ in Eq. (28) and Eq. (29) can be written as:

$$
\begin{aligned}
& \Delta P=2 \mu(1-C)\left\{\left(Q-1-\frac{1}{2} \phi^{2}\right) R_{1}+R_{2}\right\}, \\
& F_{o}=2 \mu(1-C)\left\{\left(Q-1-\frac{1}{2} \phi^{2}\right) R_{3}+R_{4}\right\} .
\end{aligned}
$$

with: $R_{1}=4 \int_{0}^{1} \frac{d z}{\left(h^{4}+\beta h^{2}\right)}, \quad R_{2}=4 \int_{0}^{1} \frac{d z}{\left(h^{2}+\beta\right)}, \quad R_{3}=4 \int_{0}^{1} \frac{d z}{\left(h^{2}+\beta\right)}, \quad R_{4}=4 \int_{0}^{1} \frac{d z}{\left(1+\frac{\beta}{h^{2}}\right)}$.

These results are the same as Saxena and Srivastava [32]. Farther more, in the peristaltic pump of Newtonian fluid in tube (i.e $C, \varepsilon, \phi_{1} \rightarrow 0$ )

$$
\begin{aligned}
& \Delta P=\frac{8}{\left(1-\phi^{2}\right)^{7 / 2}}\left\{Q\left(1+\frac{3 \phi^{2}}{2}\right)+\phi^{2} \frac{\left(\phi^{2}-16\right)}{4}\right\}, \\
& F_{o}=\frac{8}{\left(1-\phi^{2}\right)^{3 / 2}}\left\{\left(Q-1-\frac{\phi^{2}}{2}\right)+\left(1-\phi^{2}\right)^{3 / 2}\right\} .
\end{aligned}
$$


which give the same results as in Shapiro et al., [33]. In the next section, the effects of parameters on the flow will be discussed.

\section{Graphical Results and Discussion}

Using a computer programmer to evaluate the system of flow for an incompressible Newtonian fluid between two axial flexible cylinders pumping by peristaltic motion on the walls using long wavelength approximation. The research analysis results on fluid and particular phases for axial velocity, pressure drop, friction force and shear stress on inner and outer walls. Particles' radius are taken at the range $a_{1}=(0.1: 0.2)$. Figure 2 and 3 indicate how the axial velocity of fluid $u_{f}$ influenced by both $\phi$ (amplitude ratio of the outer tube) and $h$ and $\phi_{1}$ (amplitude ratio of the inner tube) and $h_{1}$ but the effects are different in two cases. $u_{f}$ increases by increasing $\phi$ and $h$ but decreases by increasing $\phi_{1}$ and $h_{1}$. The same parameters are represent in Figure 4 and 5 to investigate effects on the axial velocity of the particles $u_{p}$. These figures show that the parameters have the same manner to $u_{p}$ as in $u_{f}$ the axial velocity of particles $u_{p}$ influenced by both $\phi$ and $h$ and $\phi_{1}$ and $h_{1}$. It could be observed that $u_{p}$ increases by increasing $\phi$ and $h$ but decreases by increasing $\phi_{1}$ and $h_{1}$.

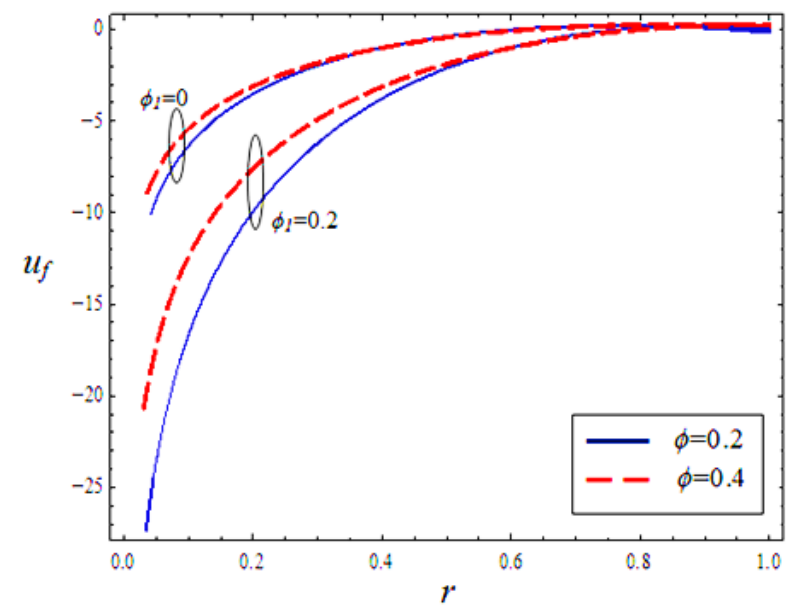

Fig. 2. $u_{f}$ with $r$ for different $\phi$ and $\phi_{1}$, ( $\varepsilon=0.4, \quad C=0.4, \quad Q=0.6, h=1+\phi$, $\left.h_{1}=\varepsilon+\phi_{1}\right)$

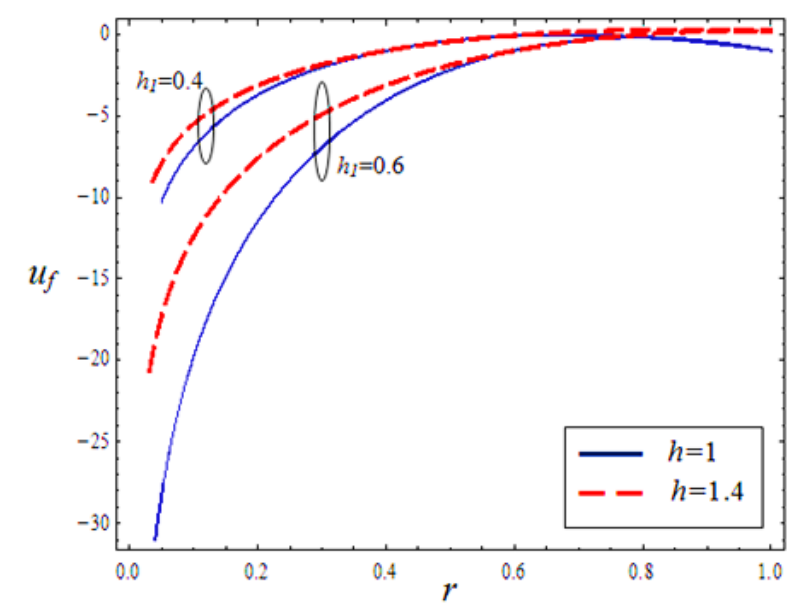

Fig. 3. $u_{f}$ with $r$ for different values of $h$ and $h_{1}$ , $\left(\phi=0.4, \phi_{1}=0.2, Q=0.6, C=0.4, \varepsilon=0.4\right)$ 


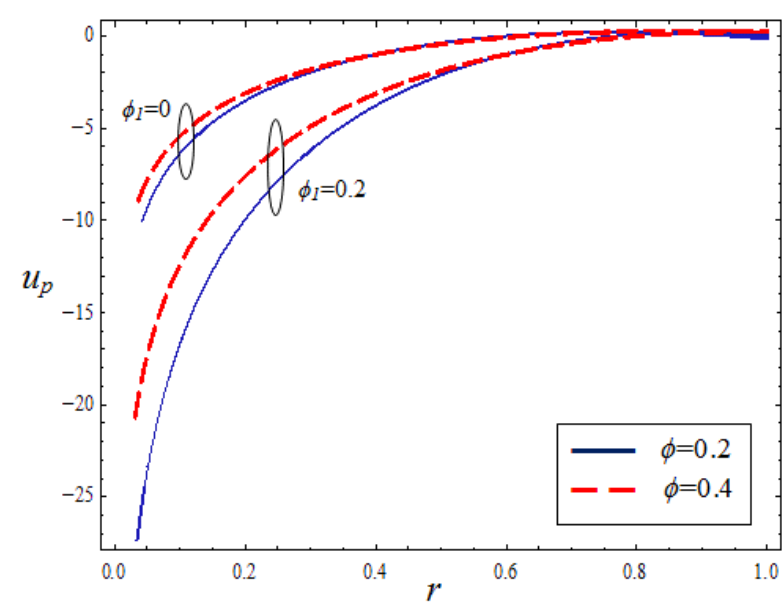

Fig. 4. $u_{p}$ with $r$ for different values of $\phi$ and $\phi_{1}$ ( $\varepsilon=0.4, C=0.4, Q=0.6, h=1+\phi$, $\left.h_{1}=\varepsilon+\phi_{1}\right)$

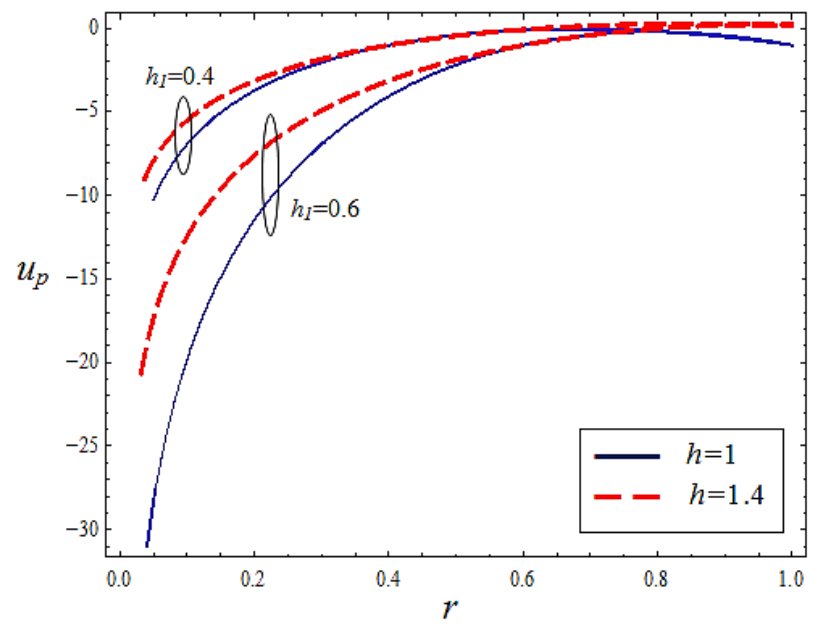

Fig. 5. $u_{p}$ with $r$ for different value of $h$ and $h_{1}$, $\left(\phi=0.4, \phi_{1}=0.2, Q=0.6, C=0.4, \varepsilon=0.4\right)$

For any given set of parameters, a liner relationship between the flow rate and the pressure drop is observed in Figure 6 and 7. In these two figures, the pressure drop $\Delta P$ increases with the flow rate $Q$ which implies that (an increase in the flow rate reduces the pressure rise ) $-\Delta P($ ) thus the maximum flow rate is accrued at zero pressure rise and the maximum pressure is achieved at zero flow rate.

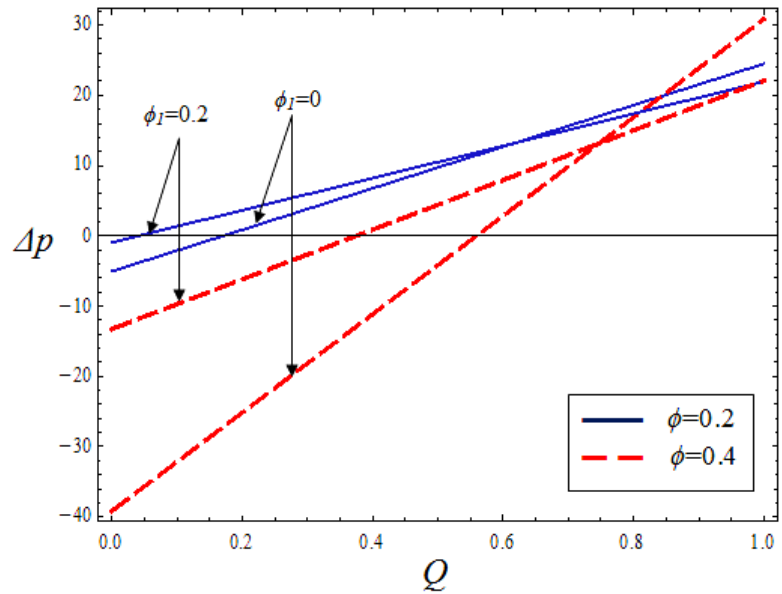

Fig. 6. $\Delta P$ with $Q$ for different value of $\phi$ and $\phi_{1},(\varepsilon=0.2, C=0.4)$

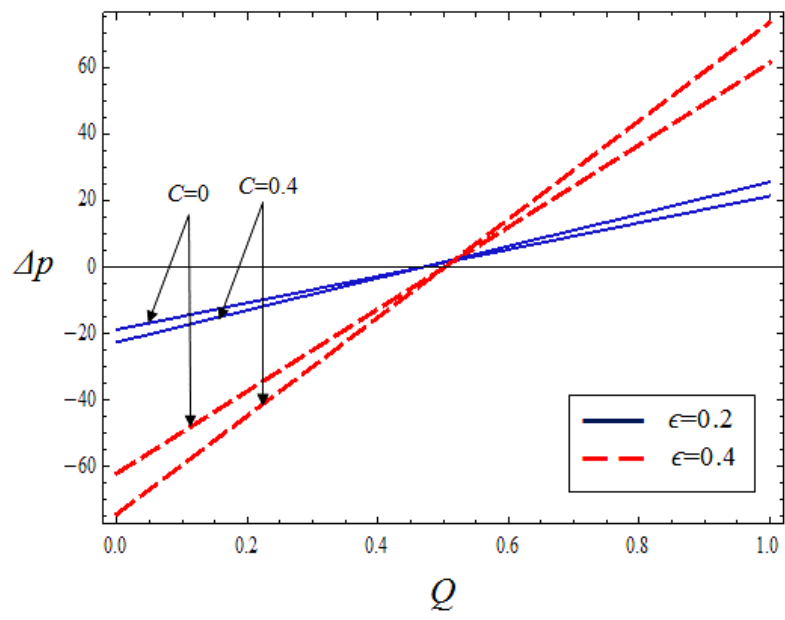

Fig. 7. $\Delta P$ with $Q$ for different value of $\varepsilon$ and $C$ $\left(\phi=0.4, \phi_{1}=0.1\right)$

It could be observed in Figure 6 and 7 that the pressure drop $\Delta P$ increases with $\phi$ (amplitude ratio of the outer tube), $\phi_{1}$ (amplitude ratio of the inner tube), $C$ (particle concentration) and $\varepsilon$ (eccentricity parameter).

The friction force at the tube wall $F_{o}$ discussed in Figure 8 and $9, F_{o}$ decreases with increasing amplitude ratio $\phi, \phi_{1}$ and $\varepsilon$ while $F_{o}$ increases with particle concentration $C$. 


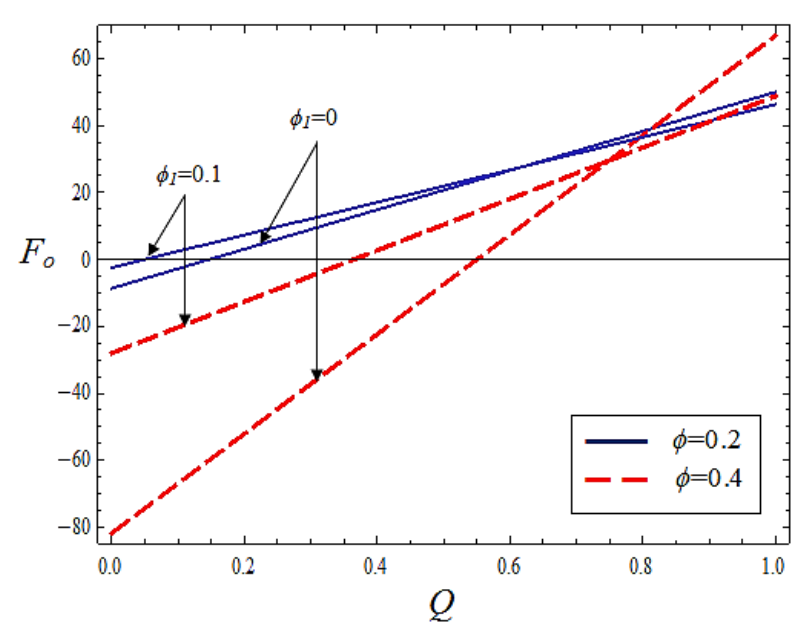

Fig. 8. $F_{o}$ with $Q$ for different values of $\phi$ and $\phi_{1}$ $(\varepsilon=0.4, C=0.4)$

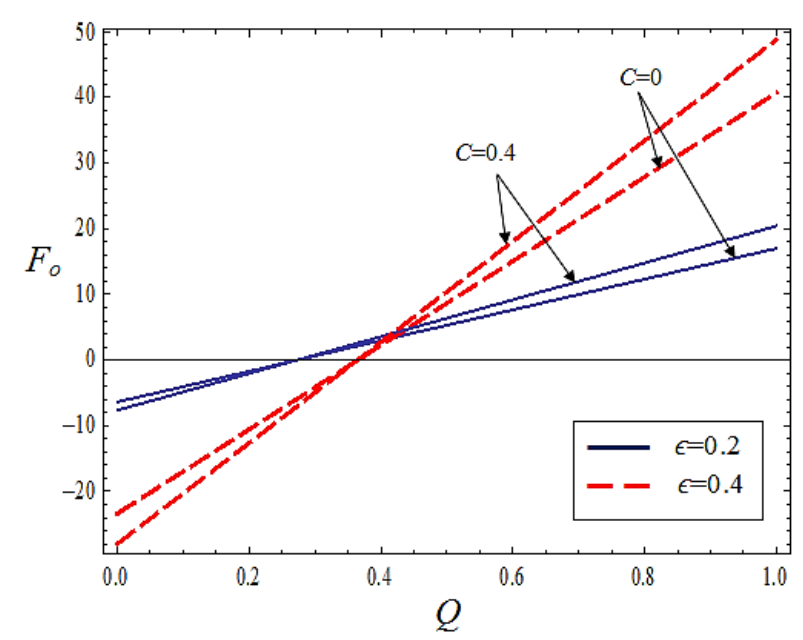

Fig. 9. $F_{o}$ with $Q$ for different value of $\varepsilon$ and $C$ $\left(\phi=0.4, \phi_{1}=0.1\right)$

Figure 10 and 11 represent how friction force on the inner tube $F_{i}$ effected by various parameters as same as on the outer tube that $F_{i}$ decreases with increasing amplitude ratio $\phi, \phi_{1}$ and $\varepsilon$ while $F_{i}$ increases with particle concentration $C$.

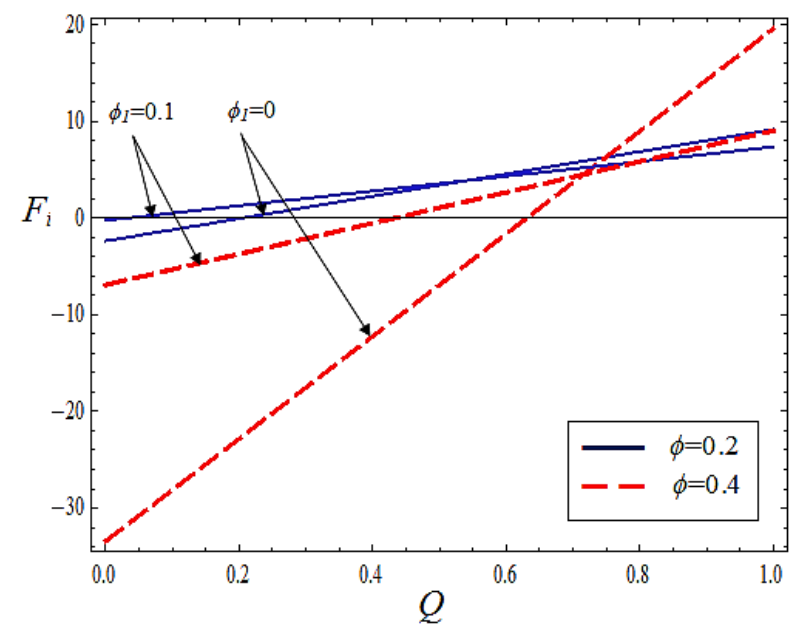

Fig. 10. $F_{i}$ with $Q$ for different values of $\phi$ and $\phi_{1}$ $(\varepsilon=0.4, C=0.4)$

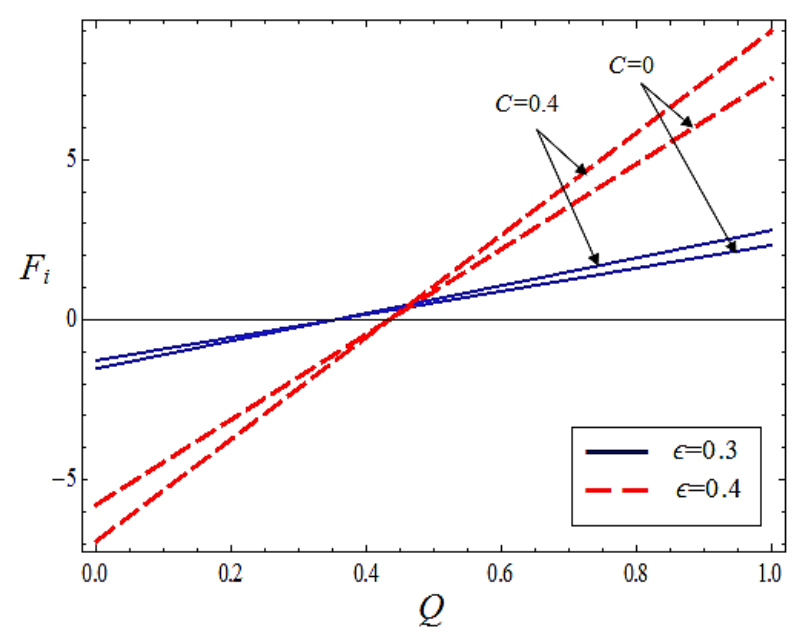

Fig. 11. $F_{i}$ with $Q$ for different values of $\varepsilon$ and $C,\left(\phi=0.4, \phi_{1}=0.1\right)$

Shear stress on the outer tube $T_{1}$ are represented in Figure 12-14 in which the shear stress increases by increasing the flow rate $Q$ while the effect of both $\phi$ and $\phi_{1}$ are not the same which appeared in Figure $12 T_{1}$ decreases by increasing $\phi$ and increases by increasing $\phi_{1}$. In Figure 13 effects of both $h$ and $h_{1}$ on $T_{1}$ which represent $T_{1}$ decreases by increasing $h$ and increases by increasing $h_{1}$. Figure 14 show that $T_{1}$ increases by increasing both $\varepsilon$ and $C$. 


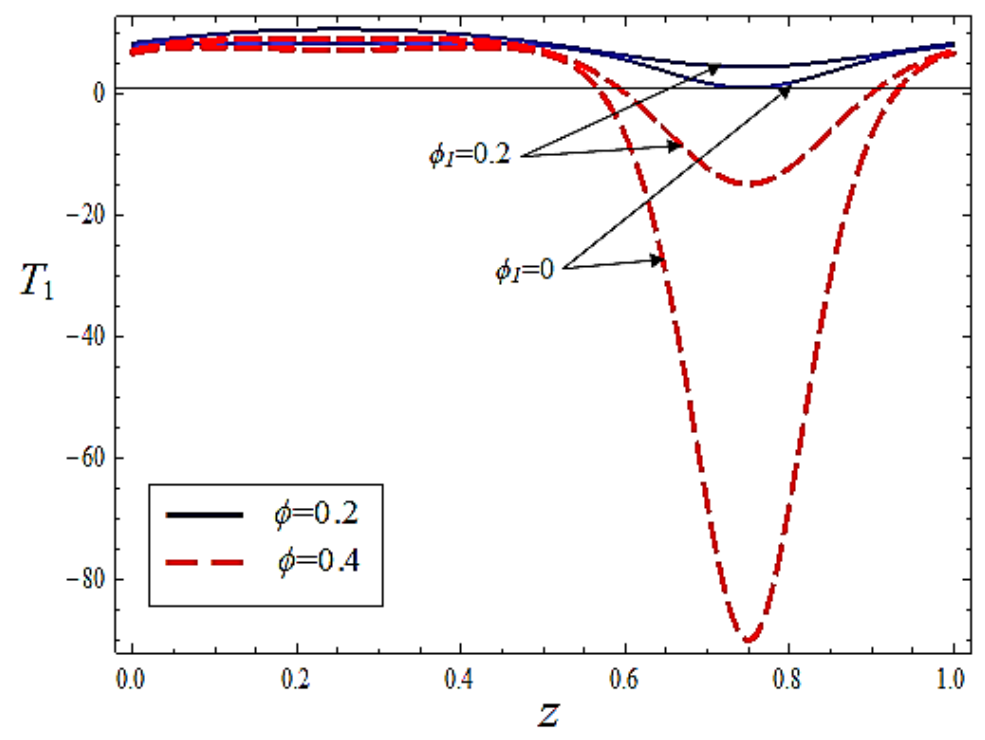

Fig. 12. $T_{1}$ with $z$ for different values of $\phi$ and $\phi_{1}$ for $(\varepsilon=0.4, C=0.4, Q=0.4)$

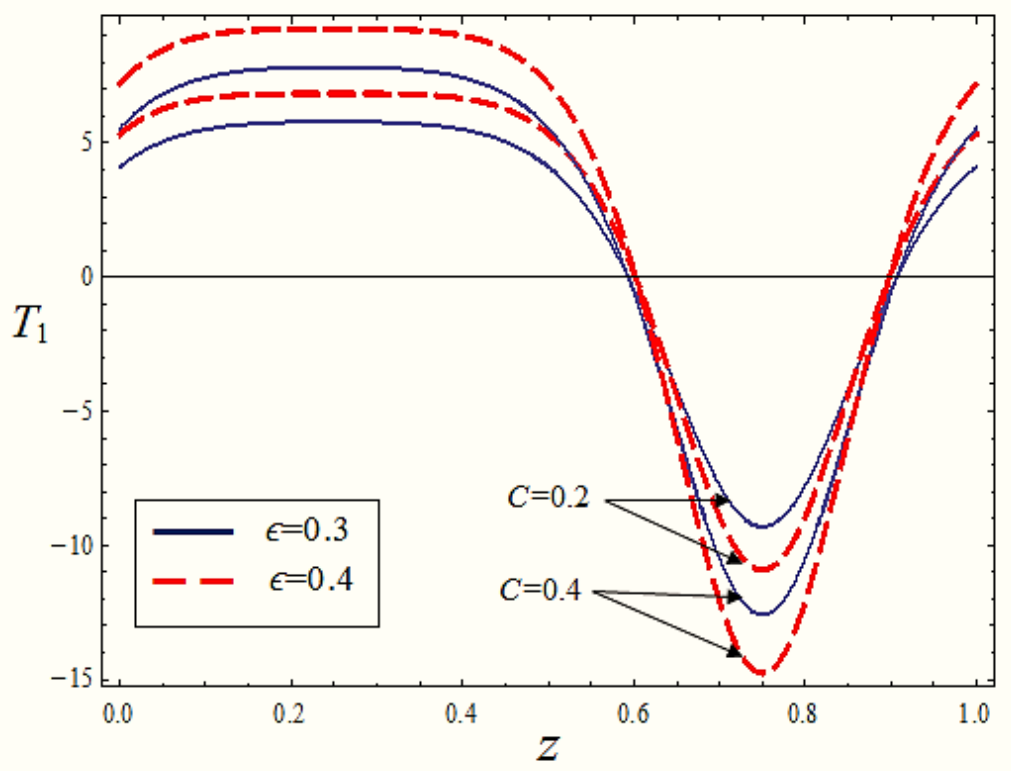

Fig. 13. $T_{1}$ with $z$ for different values of $\varepsilon$ and $C$, for $(\phi=0.4$, $\phi_{1}=0.2, Q=0.4$ ) 


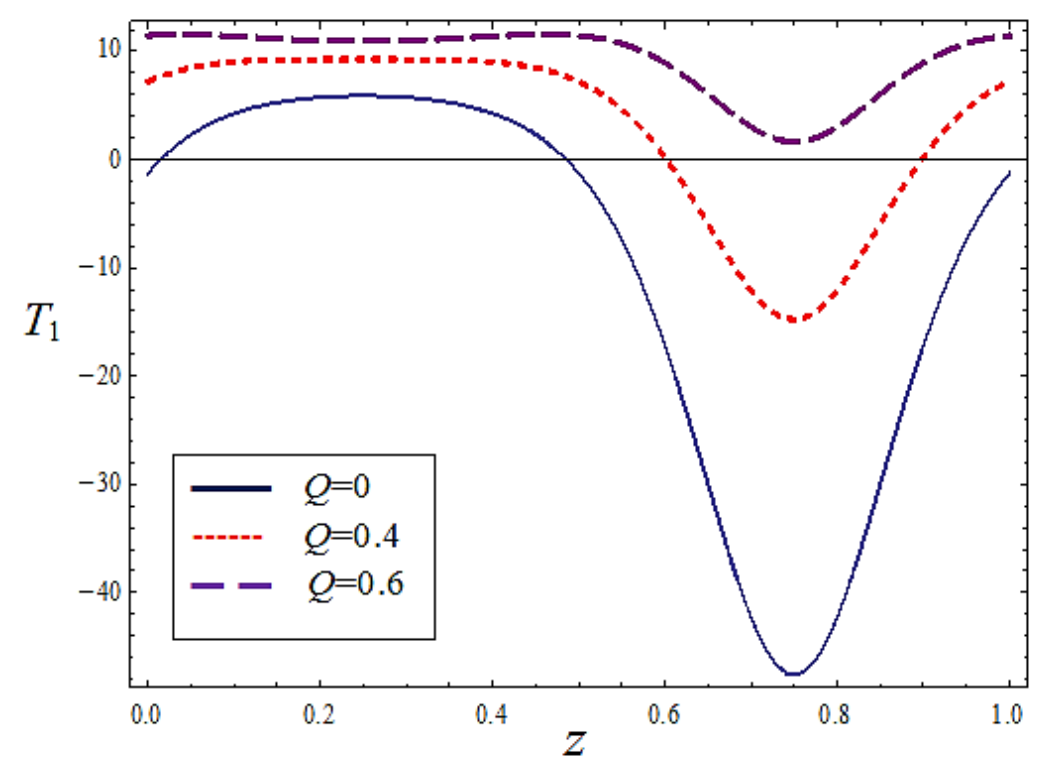

Fig. 14. $T_{1}$ with $z$ for different values of $Q\left(\phi=0.4, \phi_{1}=0.2\right.$, $\varepsilon=0.4, C=0.4$ )

Also, shear stress on the inner tube $T_{2}$ are represented in Figure 15-17 in which the shear stress decreases by increasing the flow rate $Q$ while in Figure 15 effects of both $\phi$ and $\phi_{1}$ on $T_{2} . T_{2}$ increases by increasing $\phi$ and decreases by increasing $\phi_{1}$. In Figure 16 effects of both $h$ and $h_{1}$ on $T_{2}$ which represent $T_{2}$ increases by increasing $h$ and decreases by increasing $h_{1}$. Figure 17 show that $T_{2}$ decreases by increasing both $\varepsilon$ and $C$.

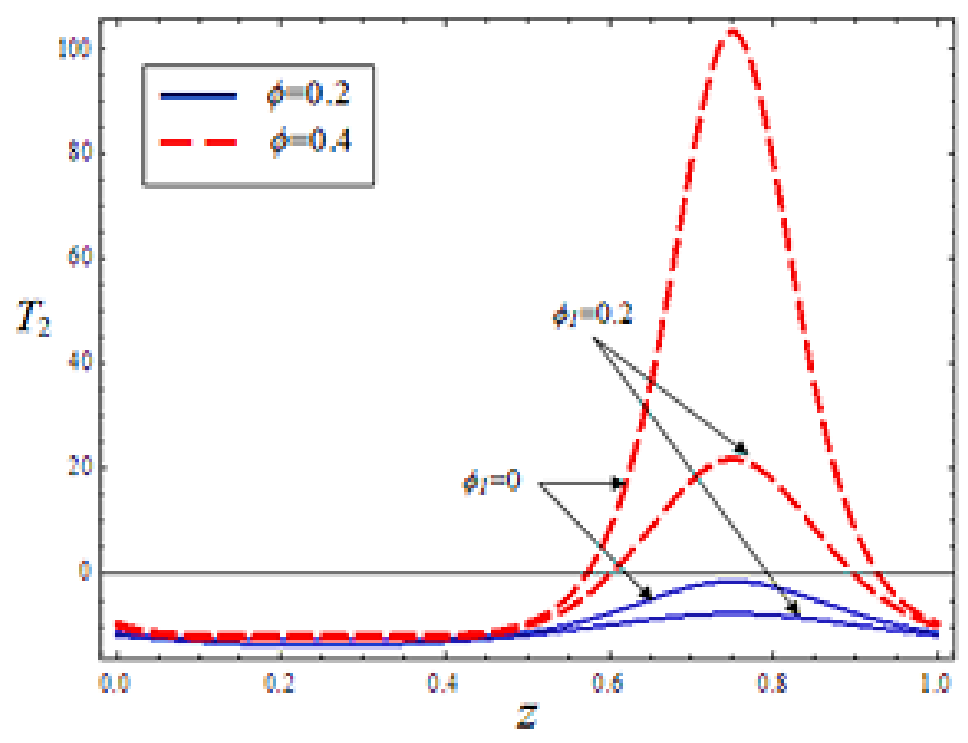

Fig. 15. $T_{2}$ with $z$ for different values of $\phi$ and $\phi_{1}$, for $(\varepsilon=0.4, C=0.4, Q=0.4$ ) 


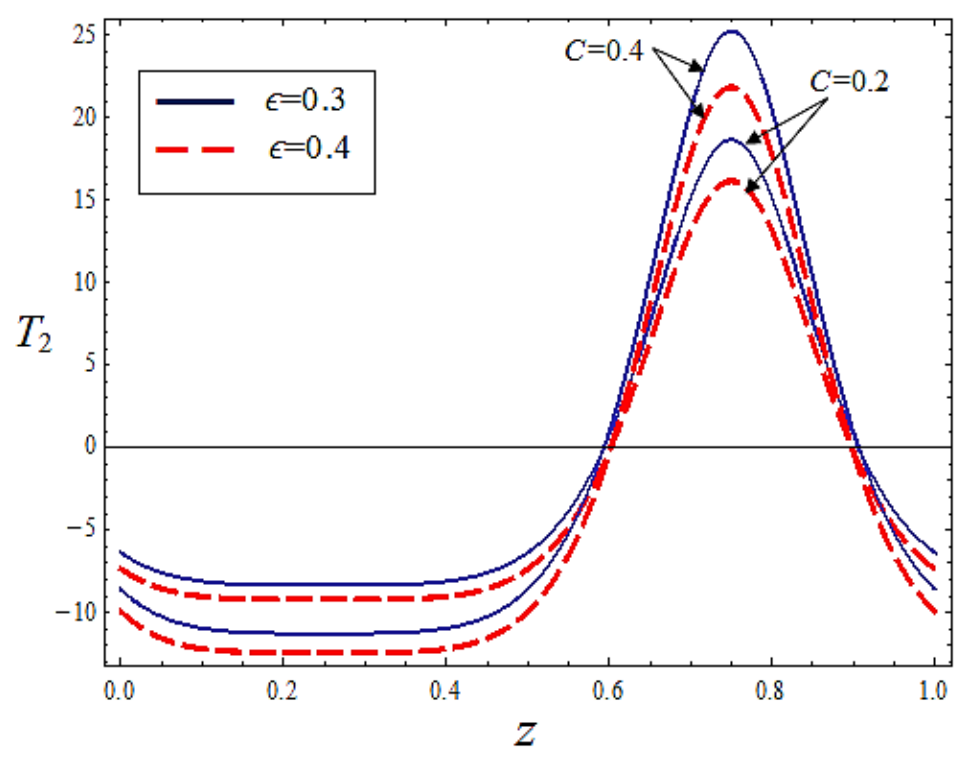

Fig. 16. $T_{2}$ with $z$ for different values of $\varepsilon$ and $C$, for $\left(\phi=0.4, \phi_{1}=0.2, Q=0.4\right)$

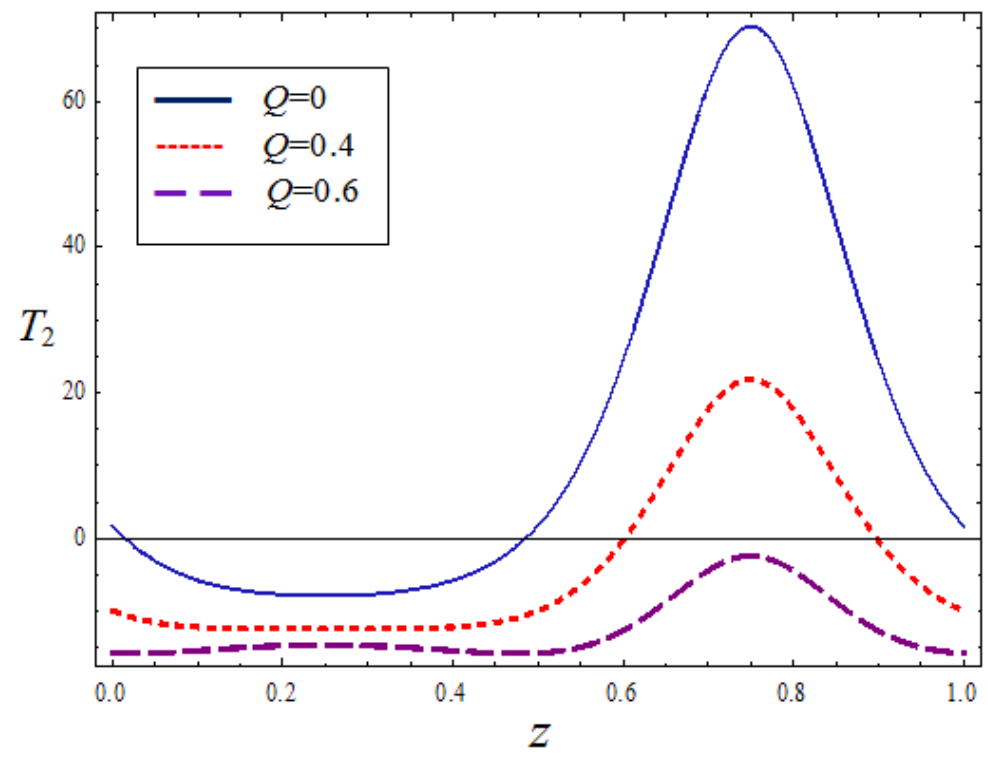

Fig. 17. $T_{2}$ with $Z$ for different values $Q$, for $(\phi=0.4$, $\phi_{1}=0.2, \varepsilon=0.4, C=0.4$ )

\section{Real Life Application}

The urinary system consists of the kidneys, ureters, bladder and urethra. It can be divided into two sections, an upper (kidneys to ureters) and a lower (bladder to urethra) sections. Under normal conditions, urine flows from the kidneys to the bladder by peristaltic action of the ureters wall. In an adult human, typical ureter dimensions and bolus velocity, as suggested for biomechanical modeling by Boyarski et al., [6], are: $a=2.5 \mathrm{~mm}, \lambda=120 \mathrm{~mm}$, and $c=30 \mathrm{~mm} / \mathrm{s}$. Urine characteristics are similar to that of water so that the density is $\rho_{f}=1000 \mathrm{~kg} / \mathrm{m}^{3}$ at $T=298 K^{o}$ and viscosity 
$\mu_{o}=0.00089 \mathrm{Ns} / \mathrm{m}^{2}$. The present study can be applied to discuss the effect of flexible endoscopy has inside the ureter. The process occurs at isothermal conditions. The major assumption in the present analysis is a two-dimensional geometry with the walls of ureter and endoscopy being represented as an infinite train of sinusoidal waves. The fluid is incompressible and Newtonian, peristalsis occurs with solid particles as in the fluid dispersion/aggregation of $\mathrm{CaO}$. In a diluted urine mixture, the particle's diameter of $\mathrm{CaO}$ crystals is approximately $2 a_{0}=10.2 \mu \mathrm{m}$ Guerra et al., [11], and the average density of these crystals is approximately $\rho_{p}=1960 \mathrm{~kg} / \mathrm{m}^{3}$ Walton et al., [43]. The value of $Q_{0} \equiv(Q)_{\triangle P=0}$ (free pumping) is of particular physiological relevance since it represents peristalsis without a prescribed pressure gradient it be represented in Table 1 flow rate for different types of endoscopy.

Table 1

Comparison between the time-mean flow rate of suspension fluid during the presence of flexible endoscopy for different radii $a_{1}$ and wave amplitudes $b_{1}$ and the time-mean flow rate of suspension fluid during the presence of traditional endoscopy

\begin{tabular}{|c|c|c|c|}
\hline $\begin{array}{l}\text { Radius of } \\
\text { endoscopy } \\
a_{1}(\mathrm{~mm})\end{array}$ & $\begin{array}{l}\text { Amplitude of } \\
\text { endoscopy } \\
b_{1}(\mathrm{~mm})\end{array}$ & $\begin{array}{l}\text { The time-mean flow } \\
\text { rate } \\
\pi a^{2} c Q_{0} \equiv Q_{\Delta p=0}\end{array}$ & $\begin{array}{l}\text { The time-mean flow rate } \\
\text { in the absence of } b_{1} \\
\pi a^{2} c Q_{0} \equiv Q_{\Delta p=0 . b_{1}=0}\end{array}$ \\
\hline 0.25 & 0.01 & 217.234 & 218.858 \\
\hline 0.3 & 0.02 & 232.887 & 237.268 \\
\hline 0.8 & 0.03 & 243.461 & 251.254 \\
\hline 1.00 & 0.04 & 255.997 & 268.138 \\
\hline 1.25 & 0.05 & 275.608 & 293.607 \\
\hline 1.5 & 0.06 & 298.619 & 323.221 \\
\hline 1.6 & 0.08 & 301.481 & 335.403 \\
\hline
\end{tabular}

\section{Conclusion}

An incompressible suspension Newtonian fluid between two axial flexible cylinders pumping by peristaltic motion on the walls is studied. Our system of equations is solved using long-wavelength approximation. The major outcomes of the investigation are featured underneath

i. $\quad u_{f}$ and $u_{p}$ increases by increasing $\phi$ (amplitudee ratio for the outer tube) but decreases by increasing $\phi_{1}$ (amplitudee ratio for the inner tube).

ii. The flow rate influenced by existing peristaltic wave on the inner tube.

iii. The pressure drop, pressure rise are disused in the presence of flexible inner tube it found that the pressure drop $\Delta P$ increases with increasing $\phi$ (amplitude ratio of the outer tube), $\phi_{1}$ (amplitude ratio of the inner tube), $C$ (particle concentration) and $\varepsilon$ (eccentricity parameter)..

iv. The friction force on inner and outer tubes are decreases with increasing ampitude ratio for the outer and inner tube $\phi$ and $\phi_{1}$ respectively.

v. The effect of flexible inner tube on shear stress: $T_{1}$ (shear stress on the outer tube) decreases by increasing $\phi$ and increases by increasing $\phi_{1}, T_{2}$ (shear stress on the inner tube) increases by increasing $\phi$ and decreases by increasing $\phi_{1}$. 
vi. The present analysis can also be reduced to Newtonian fluid by taking $C=0$, as special case of our study.

vii. This study could be applied on ureter tract in the presence of flexible endoscopy.

viii. Real data has been used to calculate the effect of flexible endoscopy on the flow in ureter tract.

ix. Finally, this work can be developed by studying other types of fluids or studying effects of new physical quantities on the flow.

\section{References}

[1] Aarts, A. C. T., and G. Ooms. "Net flow of compressible viscous liquids induced by travelling waves in porous media." Journal of engineering mathematics 34, no. 4 (1998): 435-450. https://doi.org/10.1023/A:1004314014329

[2] Antanovskii, Leonid K., and Harold Ramkissoon. "Long-wave peristaltic transport of a compressible viscous fluid in a finite pipe subject to a time-dependent pressure drop." Fluid Dynamics Research 19, no. 2 (1997): 115. https://doi.org/10.1016/50169-5983(96)00030-5

[3] Back, L. H. "Estimated mean flow resistance increase during coronary artery catheterization." Journal of biomechanics 27, no. 2 (1994): 169-175. https://doi.org/10.1016/0021-9290(94)90205-4

[4] Back, L. H., E. Y. Kwack, and M. R. Back. "Flow rate-pressure drop relation in coronary angioplasty: catheter obstruction effect." (1996): 83-89. https://doi.org/10.1115/1.2795949

[5] Baral, M. C. "Plane parallel flow of a conducting dusty gas." Journal of the Physical Society of Japan 25, no. 6 (1968): 1701-1702. https://doi.org/10.1143/JPSJ.25.1701

[6] Boyarsky, S., Gottschalk, C. W., \& Tanagho, E. A. (2014). Urodynamics: hydrodynamics of the ureter and renal pelvis. Academic Press.

[7] Charm, Stanley E., and George S. Kurland. Blood flow and microcirculation. Wiley, 1974.

[8] Misery, AM EL, Elsayed F. Elshehawey, and A. A. Hakeem. "Peristaltic motion of an incompressible generalized Newtonian fluid in a planar channel." Journal of the Physical Society of Japan 65, no. 11 (1996): 3524-3529. https://doi.org/10.1143/JPSJ.65.3524

[9] Fung, Y. C., and C. S. Yih. "Peristaltic transport." (1968): 669-675. https://doi.org/10.1115/1.3601290

[10] Grove, Jay R., and William C. Pevec. "Venous thrombosis related to peripherally inserted central catheters." Journal of Vascular and Interventional Radiology 11, no. 7 (2000): 837-840. https://doi.org/10.1016/S1051-0443(07)617977.

[11] Guerra, Angela, Franca Allegri, Tiziana Meschi, Giuditta Adorni, Beatrice Prati, Antonio Nouvenne, Almerico Novarini, Umberto Maggiore, Enrico Fiaccadori, and Loris Borghi. "Effects of urine dilution on quantity, size and aggregation of calcium oxalate crystals induced in vitro by an oxalate load." Clinical Chemistry and Laboratory Medicine (CCLM) 43, no. 6 (2005): 585-589. https://doi.org/10.1515/CCLM.2005.102

[12] Hung, Tin-Kan, and Thomas D. Brown. "Solid-particle motion in two-dimensional peristaltic flows." Journal of Fluid Mechanics 73, no. 1 (1976): 77-96. https://doi.org/10.1017/S0022112076001262

[13] Jaffrin, M. Y., and A. H. Shapiro. "Peristaltic pumping." Annual review of fluid mechanics 3, no. 1 (1971): 13-37. https://doi.org/10.1146/annurev.fl.03.010171.000305

[14] Jiménez-Lozano, Joel, Mihir Sen, and Patrick F. Dunn. "Particle motion in unsteady two-dimensional peristaltic flow with application to the ureter." Physical Review E 79, no. 4 (2009): 041901. https://doi.org/10.1103/PhysRevE.79.041901

[15] MacDonald, D. A. "Pulsatile flow in a catheterised artery." Journal of Biomechanics 19, no. 3 (1986): 239-249. https://doi.org/10.1016/0021-9290(86)90156-9

[16] Mangan, Elizabeth V., Dan A. Kingsley, Roger D. Quinn, and Hillel J. Chiel. "Development of a peristaltic endoscope." In Proceedings 2002 IEEE International Conference on Robotics and Automation (Cat. No. 02CH37292), vol. 1, pp. 347-352. IEEE, 2002.

[17] Medhavi, Amit. "Peristaltic pumping of a particulate suspension in a catheterized tube." (2015).

[18] Medhavi, Amit, and U. K. Singh. "A two-layered suspension flow induced by peristaltic waves." International Journal of Fluid Mechanics Research 35, no. 3 (2008). https://doi.org/10.1615/InterJFluidMechRes.v35.i3.40

[19] Medhavi, A., and U. K. Singh. "Peristaltic pumping of a two-layered particulate suspension in a circular cylindrical tube." Int. J. Theo. and Appl. Mech 3 (2009): 265-280.

[20] Mekheimer, Kh S., Y. Abd Elmaboud, and A. I. Abdellateef. "Particulate suspension flow induced by sinusoidal peristaltic waves through eccentric cylinders: thread annular." International Journal of Biomathematics 6, no. 04 (2013): 1350026. https://doi.org/10.1142/S1793524513500265

[21] Mekheimer, Kh S., Elsayed F. El Shehawey, and A. M. Elaw. "Peristaltic motion of a particle-fluid suspension in a 
planar channel." International Journal of Theoretical Physics 37, no. $11 \quad$ (1998): 2895-2920. https://doi.org/10.1023/A:1026657629065

[22] Ramadan, Shaimaa Fathey, and Kh S. Mekheimer. "New Insight into Gyrotactic Microorganisms in Anti-Infection Agents Through Wavy Deformable Catheter/Endoscope with Non-Linear Thermal Radiation: Numerical Study." Journal of Advanced Research in Fluid Mechanics and Thermal Sciences 75, no. 3 (2020): 25-42. https://doi.org/10.37934/arfmts.75.3.2542

[23] Muthuraj, R., K. Nirmala, and S. Srinivas. "Influences of chemical reaction and wall properties on MHD peristaltic transport of a dusty fluid with heat and mass transfer." Alexandria Engineering Journal 55, no. 1 (2016): 597-611. https://doi.org/10.1016/i.aej.2016.01.013

[24] Nagarani, P., G. Sarojamma, and G. Jayaraman. "Exact analysis of unsteady convective diffusion in Casson fluid flow in an annulus-Application to catheterized artery." Acta mechanica 187, no. 1 (2006): 189-202. https://doi.org/10.1007/s00707-006-0316-9

[25] Rachid, H., and M. T. Ouazzani. "Interaction of pulsatile flow with peristaltic transport of a viscoelastic fluid: case of a Maxwell fluid." International Journal of Applied Mechanics 6, no. 05 (2014): 1450061. https://doi.org/10.1142/S1758825114500616

[26] Rachid, H., and M. T. Ouazzani. "Electro-magnetohydrodynamic Peristaltic Pumping of a Biviscosity Fluid Between Two Coaxial Deformable Tubes Through a Porous Medium." Acta Physica Polonica B 48, no. 9 (2017): $1515-1527$. https://doi.org/10.5506/APhysPolB.48.1515

[27] Rao, P. S. "Unsteady flow of a dusty viscous liquid through circular cylinder." Def. Sci. J. 19 (1969): $135-138$.

[28] Roos, Rudolf, and Paul S. Lykoudis. "The fluid mechanics of the ureter." Journal of Fluid Mechanics 46, no. 4 (1971): 625-630. https://doi.org/10.1017/S0022112071000752

[29] Saffman, P. G. "On the stability of laminar flow of a dusty gas." Journal of fluid mechanics 13, no. 1 (1962): $120-128$. https://doi.org/10.1017/S0022112062000555

[30] Sankar, D. S., and K. Hemalatha. "Pulsatile flow of Herschel-Bulkley fluid through catheterized arteries-A mathematical model." Applied Mathematical Modelling 31, $\quad$ no. $8 \quad$ (2007): $1497-1517$. https://doi.org/10.1016/i.apm.2006.04.012

[31] Sarkar, A., and G. Jayaraman. "Correction to flow rate-pressure drop relation in coronary angioplasty: steady streaming effect." Journal of Biomechanics 31, no. 9 (1998): 781-791. https://doi.org/10.1016/S00219290(98)00053-0

[32] Saxena, Meenu, and Vijai P. Srivastava. "Particulate suspension flow induced by sinusoidal peristaltic waves." Japanese journal of applied physics 36, no. 1R (1997): 385. https://doi.org/10.1143/JJAP.36.385

[33] Shapiro, Ascher H., Michel Yves Jaffrin, and Steven Louis Weinberg. "Peristaltic pumping with long wavelengths at low Reynolds number." Journal of fluid mechanics 37, no. $4 \quad$ (1969): $799-825$. https://doi.org/10.1017/S0022112069000899

[34] Srivastava, V. P., and M. Saxena. "A two-fluid model of non-Newtonian blood flow induced by peristaltic waves." Rheologica Acta 34, no. 4 (1995): 406-414. https://doi.org/10.1007/BF00367155

[35] Srivastava, L. M., and V. P. Srivastava. "Peristaltic transport of blood: Casson model-II." Journal of Biomechanics 17, no. 11 (1984): 821-829. https://doi.org/10.1016/0021-9290(84)90140-4

[36] Srivastava, L. M., and V. P. Srivastava. "Peristaltic transport of a particle-fluid suspension." (1989): $157-165$. https://doi.org/10.1115/1.3168358

[37] Srivastava, V. P., and L. M. Srivastava. "Effects of Poiseuille flow on peristaltic transport of a particulate suspension." Zeitschrift für angewandte Mathematik und Physik ZAMP 46, no. 5 (1995): 655-679. https://doi.org/10.1007/BF00949072

[38] Srivastava, V. P., and L. M. Srivastava. "Influence of wall elasticity and Poiseuille flow on peristaltic induced flow of a particle-fluid mixture." International journal of engineering science 35, no. 15 (1997): 1359-1386. https://doi.org/10.1016/S0020-7225(97)00053-0

[39] Srivastava, V. P. "A theoretical model for blood flow in small vessels." Applications and Applied Mathematics: An International Journal (AAM) 2, no. 1 (2007): 5.

[40] Srivastava, V. P., and Rashmi Srivastava. "Particulate suspension blood flow through a narrow catheterized artery." Computers \& Mathematics with Applications 58, no. $2 \quad$ (2009): $227-238$. https://doi.org/10.1016/j.camwa.2009.01.041

[41] Takabatake, S., and K. Ayukawa. "Numerical study of two-dimensional peristaltic flows." Journal of Fluid Mechanics 122 (1982): 439-465. https://doi.org/10.1017/S0022112082002304

[42] Tam, Christopher KW. "The drag on a cloud of spherical particles in low Reynolds number flow." Journal of Fluid Mechanics 38, no. 3 (1969): 537-546. https://doi.org/10.1017/S0022112069000322

[43] Walton, R. C., J. P. Kavanagh, and B. R. Heywood. "The density and protein content of calcium oxalate crystals precipitated from human urine: a tool to investigate ultrastructure and the fractional volume occupied by organic 
matrix." Journal of structural biology 143, no. 1 (2003): 14-23. https://doi.org/10.1016/S1047-8477(03)00117-5

[44] Wu, Xianren, Wolfgang Studer, Thomas Erb, Karl Skarvan, and Manfred D. Seeberger. "Competence of the internal jugular vein valve is damaged by cannulation and catheterization of the internal jugular vein." The Journal of the American Society of Anesthesiologists 93, no. 2 (2000): 319-324. https://doi.org/10.1097/00000542-200008000$\underline{00007}$

[45] https://images.app.goo.gl/vpbrJY5JRz46NVw89 